\title{
Seedcoat Permeability: Uptake and Post-germination Transport of Applied Model Tracer Compounds
}

\author{
Yuliya A. Salanenka and Alan G. Taylor ${ }^{1}$ \\ Department of Horticulture, New York State Agricultural Experiment Station, \\ Cornell University, Geneva, NY 14456
}

Additional index words. coumarin, rhodamine, fluorescein, tetrazolium, semipermeability, log $K_{\text {ow }}$, charge, Fabaceae, Liliaceae, Solanaceae, Cucurbitaceae, Asteraceae

\begin{abstract}
The seedcoat permeability, uptake, and transport of model fluorescent tracers were investigated in snapbean (Phaseolus vulgaris), pepper (Capsicum annuum), tomato (Solanum lycopersicum), onion (Allium cepa), cucumber (Cucumis sativus), and lettuce (Lactuca sativa) seeds. Nine fluorescent tracers and one vital stain were selected to represent a diversity of physicochemical properties (lipophilicity, electrical charge, etc.) and to simulate behavior of applied seed treatments. To study seedcoat permeability, tracers were applied to seeds as dry powders, and treated seeds were sown in moistened sand at $20^{\circ} \mathrm{C}$ and removed after 18 to $24 \mathrm{~h}$, a time before visible germination. Imbibed seeds were dissected and fluorescence (staining) was observed in embryos with a dissecting microscope under ultraviolet $(365 \mathrm{~nm})$ or visible radiation. Seedcoat permeability of species to solutes was grouped into three categories: 1) permeable-snapbeans; 2) selectively permeable - tomato, pepper, and onion; and 3) non-permeable - cucumber and lettuce. Systemic tracers that failed to permeate seedcoats during seed imbibition were taken up by roots or hypocotyls after visible germination.
\end{abstract}

Seed treatments are widely used in agriculture and have desirable properties as pesticides, disinfectants, or plant growth regulators (Taylor, 2003). Many seed treatment active materials have systemic activity providing protection of the aboveground portion of plants for efficient early-season pest protection (Nault et al., 2004). However, movement of a systemic seed treatment from the seed surface to the imbibed or germinated seed is not well understood. Seed treatments may be applied in an aqueous solution as a soak or during priming to infuse active materials into the embryo or eradicate an internal seed pathogen (Taylor et al., 1998). These seed treatments must penetrate the seedcoat or seed-covering tissues to be effective before visible germination.

Uptake of compounds applied as seed treatments were examined in different vegetable crop seeds with different pesticides. The herbicide dichlorophenoxyacetic acid was effectively absorbed by pea (Pisum sativum) seeds (Hansen and Buchholtz, 1952) and mustard (Brassica sp.) (Mitchell and Brown, 1947). In contrast, the seedcoat was a barrier for atrazine uptake in turnip (Brassica rapa) (Hocombe, 1968), for the herbicide dipropetryn in cucur-

Received for publication 2 Oct. 2009. Accepted for publication 28 Jan. 2011.

Partial funding was provided by the American Seed Research Foundation, New York Onion Research and Development Program, and Multi-State project W-2168.

Helpful suggestions and technical assistance were provided by M. Goffinet and S. Pollicove.

${ }^{1}$ To whom reprint requests should be addressed; e-mailagt1@cornell.edu. bit seeds (Rubin and Demeter, 1986), and the systemic insecticide phorate in mustard (Sinapis alba) (Bardner, 1964). These collective results provide evidence that seedcoat permeability differed by crop and by compound. However, the same compound was not tested on several vegetable crop seeds so broader conclusions cannot be drawn from these studies. Therefore, an understanding is needed of the physical-chemical nature of compounds in relation to seedcoat permeability of different vegetable crop seeds.

An understanding of systemic uptake of compounds is based on uptake by plant roots and the major chemical properties are lipophilicity, electrical charge, molecular weight, and H-bonding capacity. Lipophilicity is a measure of the affinity of compounds for the lipid phase of plant tissues (plasma membrane, waxes, cutin, suberin, etc). Lipophilicity is quantified as $\log K_{\text {ow }}$ (where $K_{\text {ow }}$ is the octan$1-\mathrm{ol} /$ water partition coefficient). The relationship of $\log K_{\text {ow }}$ and plant tissue uptake reveals a Gaussian curve with a range from -1 to $5 \mathrm{log}$ $K_{\text {ow }}$ with a maximum at $\log K_{\text {ow }}$ of 2 (Briggs et al., 1982). Moderately lipophilic compounds $\left(\log K_{\text {ow }} \approx 2\right)$ are systemic because they permeate the lipid phase of cell membranes in comparison with hydrophilic compounds that are not able to pass through lipid barriers (Briggs et al., 1982). Compounds with high $\log K_{\text {ow }}$ (greater than 5) are not systemic because they are strongly retained in the plant lipid constituents (Edgington, 1981) and have limited water solubility. The electrical charge of molecules influences compound diffusion through plasma membranes, and positively charged molecules are often bound by negatively charged cell walls
(Edgington and Peterson, 1977). Hydrogenbond donor and acceptor groups on molecules decrease permeability of molecules through the lipid bilayer of cell membranes. The optimal number of H-donors and acceptors was less than 5 and 10, respectively, based on Lipinski parameters (Tice, 2001). According to Briggs (1997), the "limiting" number of $\mathrm{H}$-donors for agrochemicals is three. Increasing molecular weight impaired molecule penetration across the plasma membrane (Lipinski et al., 1997). Mobile agrochemicals have a molecular weight of $\approx 300$ or less (Briggs, 1997).

The majority of earlier studies used radioactive tracer techniques $\left({ }^{14} \mathrm{C}\right.$ radiolabeling) to study movement of compounds in seeds and roots. Use of labeled compound has many disadvantages, including cost, availability, safety, and disposal. Thus, there was a need for other tracers that would be convenient for routine laboratory use, readily available, and are visualized to examine seedcoat permeability. The fluorescent tracer, coumarin 151 , was successfully used in our laboratory to examine snapbean and cucumber seedcoat permeability (Salanenka and Taylor, 2008). The number of tracers was expanded for this study and included 10 model compounds to represent a diverse array of chemical structures and giving special attention to the value of $\log K_{\text {ow }}$, charge, molecular weight, and H-bonding capacity.

The first objective of this article was to study seedcoat permeability of selected species with different morphology and anatomy using fluorescent tracers as model compounds. The research question was to examine the pathway that systemic seed treatments take after being sown in a moist medium: 1) whether seed treatments can diffuse through the seedcoat and then to the embryo; or 2) if seed treatments cannot permeate the seedcoat, so they diffuse in the soil medium and are taken up by roots. The second objective was to study water potential of the soil environment and relative humidity of the air on seedcoat permeability. The third objective was to visualize systemic compound uptake in seedlings.

\section{Materials and Methods}

Plant materials. Seeds of six crops were used in the study: lettuce 'Waldmann's Green' (Harris Seeds, Rochester, NY), snapbean 'Hystyle' and pepper 'Beyton Bell' (Harris Moran Seed Co., Modesto, CA), tomato 'Facundo' (Syngenta Seeds, Golden Valley, MN), cucumber 'Vlaspik' (Seminis Inc., Oxnard, CA), and onion 'Millennium' (Nunhems, Parma, ID). Seeds used in the experiment did not have physiological or seedcoat-imposed dormancy based on standard germination tests.

Chemicals. Nine fluorescent dyes and one color-forming compound of various chemical classes were selected for their different values of $\log \mathrm{K}_{\mathrm{ow}}$ and electrical charge (Table 1). Coumarins, coumarin 1 [2H-1-Benzopyran-2one, 7-(diethylamino)-4-methyl-] and coumarin 151 [2H-1-Benzopyran-2-one, 7-amino-4-(trifluoromethyl)-], are both nonionic, lipophilic 
compounds. AMCA (2H-1-Benzopyran-3-acetic acid, 7-amino-4-methyl-2-oxo-) is an anionic tracer. The xanthenes, rhodamine B [Xanthylium, 9-(2-carboxyphenyl)-3,6-bis(diethylamino)-, chloride (1:1)] and sulforhodamine B [Xanthylium, 3,6-bis(diethylamino)-9-(2,4disulfophenyl)-, inner salt, sodium salt (1:1)], are zwitterionic compounds. Fluorescein \{Spiro[isobenzofuran-1(3H),9'-(9H)xanthen]-3-one \}, 5(6)-carboxyfluorescein \{Spiro[isobenzofuran1(3H), 9'- $(9 \mathrm{H})$ xanthene]-ar-carboxylic acid, 3',6'-dihydroxy-3-oxo- $\}$, and uranine $\{$ Spiro[isobenzofuran-1(3H), 9' -(9H)xanthen]-3one, 3',6'-dihydroxy-, sodium salt (1:2)\} are anionic. Acridine (9-aminoacridine) is cationic. Tetrazole, tetrazolium red $(2,3,5-$ Triphenyl-2H-tetrazolium chloride) is cationic and colorless in water. The tetrazolium salt is a viability stain and is biochemically reduced to the water-insoluble dye, formazan red, by cellular dehydrogenase activity. In addition, each compound's pKa, molecular weight, and H-donors and acceptors were provided (Table 1). All chemicals were purchased from Sigma-Aldrich Co. (St. Louis, MO).

Dye application and microscopy. Tracers were applied to seeds as dry powders to avoid exposure to water during the treatment stage. The application rate was $0.5 \mathrm{~g}$ tracer per $100 \mathrm{~g}$ seeds, and the excess powder was removed though a sieve. Five replications of 20 seeds per replication of each treatment were sown in sand pre-moistened with water at $20^{\circ} \mathrm{C}$ and excavated after 18 to $24 \mathrm{~h}$, a time before visible germination. For cucumber seedling uptake studies, treated seeds were sown and seedling parts excised after the first true leaves had developed. The location and intensity of fluorescence in hand-dissected imbibed seeds or seedlings were observed under long ultraviolet $(365 \mathrm{~nm})$ radiation with an Olympus SZX12 stereomicroscope (Center Valley, PA) equipped with a SPOT Insight camera and software (Version 4.5; Sterling Heights, MI). Detection of the fluorescent tracers in the embryo was qualitative, and seed tissue autofluorescence, if present, did not interfere with observing the tracers.

Coumarin uptake by snapbean seeds under different water regimes. Snapbean seeds were used to study tracer uptake under soil water stress conditions and in air at $100 \%$ relative humidity (RH). For the water stress treatments, polyethylene glycol 8000 (PEG) solutions were prepared to obtain different water potentials (Michel, 1983). Seeds were treated with coumarin 1 powder, placed in sand moistened with solutions of $0 \mathrm{MPa}$ (water), $-1 \mathrm{MPa}$ or -2 $\mathrm{MPa}$ water potential, and incubated in loosely sealed containers at $25^{\circ} \mathrm{C}$. For the $100 \% \mathrm{RH}$ treatment, coumarin 1-treated seeds were placed on screens above water in closed containers producing a water vapor saturated atmosphere at $25{ }^{\circ} \mathrm{C}$. Seeds were examined for dye penetration after $0.5,2,4$, and $6 \mathrm{~d}$.

\section{Results}

\section{Seedcoat permeability}

Snapbean. Seedcoat permeability of snapbean to applied tracers is shown in Figure 1.
Seedcoats were permeable to most fluorescent tracers and the tetrazolium salt. On removal of seedcoats from seed after $18 \mathrm{~h}$ of imbibition in sand, strong uniform fluorescence was present on the embryo with coumarins, fluorescein, carboxyfluorescein, uranine, and AMCA showing that seedcoats were highly permeable to these tracers. Time course studies revealed that these tracers diffused uniformly over the seedcoat and not first through the hilum or micropyle (data not shown). Tetrazolium red, 9-aminoacridine, and rhodamine B penetrated the seedcoats; however, fluorescence or red formazan coloration on the surface of the cotyledons was not distributed uniformly. Sulforhodamine B showed limited staining and only irregularly on the embryo.

Onion, tomato, and pepper. Seedcoat permeability of tomato, pepper, and onion to applied tracers is shown in Figure 2. The comparative observation showed that tomato, onion, and pepper seeds were only permeable to nonionic fluorescent tracers (coumarin 1 and 151), and embryo tissue revealed strong fluorescence after seed imbibition and before radicle emergence. No other tracers were detected in the endosperm or embryo tissues.
Lettuce and cucumber. For all tracers, fluorescence or staining was not observed in the embryo tissue after imbibition of lettuce and cucumber seeds (Fig. 3). The tracers were able to diffuse through the testa of cucumber seed but did not permeate the inner seed envelope (perisperm-endosperm envelope) surrounding the cotyledons.

\section{Pathways of tracer uptake into seed tissue}

One pathway of movement of nonionic lipophilic tracers (coumarin 1 or coumarin 151) was through the seedcoat to the endosperm and embryo tissues in onion (Fig. 4A). These tracers diffused through the seedcoats before visible germination. In contrast, a charged molecule of rhodamine $\mathrm{B}$ was not able to permeate the onion seedcoat (Fig. 4B) but was absorbed by the radicle after visible germination (Fig. 4C).

\section{Coumarin uptake by snapbean seeds under different moisture regimes}

Uptake of tracers by snapbean seed at various water potentials and $100 \% \mathrm{RH}$ are summarized at Table 2. Uptake was rapid in

Table 1. Physicochemical properties of fluorescent tracers and one vital stain used to assess seedcoat permeability of selected vegetable crop seeds.

\begin{tabular}{lclccc}
\hline Compound & $\log \mathrm{K}_{o w}$ & Charge state & $\mathrm{pKa}$ & $\mathrm{MW}^{\mathrm{z}}$ & H-donors/acceptors $^{\mathrm{z}}$ \\
\hline Coumarin 1 (C1) & $3.2^{\mathrm{z}}$ & Nonionic & $3.3^{\mathrm{v}}$ & 231.3 & $0 / 3$ \\
Coumarin 151 (C151) & $1.6^{\mathrm{z}}$ & Nonionic & $3.3^{\mathrm{v}}$ & 229.2 & $2 / 3$ \\
AMCA (coumarin) & $0.9^{\mathrm{z}}$ & Anionic & 3.9 & 233.2 & $3 / 5$ \\
Rhodamine B (RhD) & $1.5^{\mathrm{y}}$ & Zwitterionic $^{\mathrm{u}}$ & $3.0^{\mathrm{x}}$ & 479.0 & $1 / 5$ \\
Sulforhodamine B (SRh) & $-2.0^{\mathrm{x}}$ & Zwitterionic $^{\mathrm{u}}$ & $<1.5^{\mathrm{x}}$ & 580.6 & $0 / 8$ \\
Fluorescein (FL) & $1.8^{\mathrm{w}}$ & Anionic $^{\mathrm{w}}$ & $4.4^{\mathrm{w}}$ & 332.3 & $2 / 5$ \\
Uranine (UR) & $-1.3^{\mathrm{x}}$ & Anionic & $5.1^{\mathrm{x}}$ & 376.3 & $0 / 5$ \\
Carboxyfluorescein (CF) & $-1.9^{\mathrm{w}}$ & Anionic & $4.1^{\mathrm{w}}$ & 376.3 & $3 / 7$ \\
9-Aminoacridine (Acr) & $-1.4^{\mathrm{t}}$ & Cationic & $9.9^{\mathrm{t}}$ & 194.2 & $2 / 2$ \\
Tetrazolium red (TZ) & $-2.4^{\mathrm{v}}$ & Cationic & - & 384.9 & $0 / 4$ \\
\hline
\end{tabular}

${ }^{2}$ Values obtained from ChemSpider database: Pred.Prop. (EPISuite) $(<\mathrm{http}: / /$ www.chemspider.com $>$ ).

'Liu and Gaskin (2004).

${ }^{x}$ Kasnavia et al. (1999).

"Wang et al. (2000).

vValues calculated by ALOGPS Version 2.1. ( $<\mathrm{http}: / /$ vcclab.org $>)$.

"Gilliland et al. (2005).

tHorobin et al. (2006)

$\mathrm{MW}=$ molecular weight

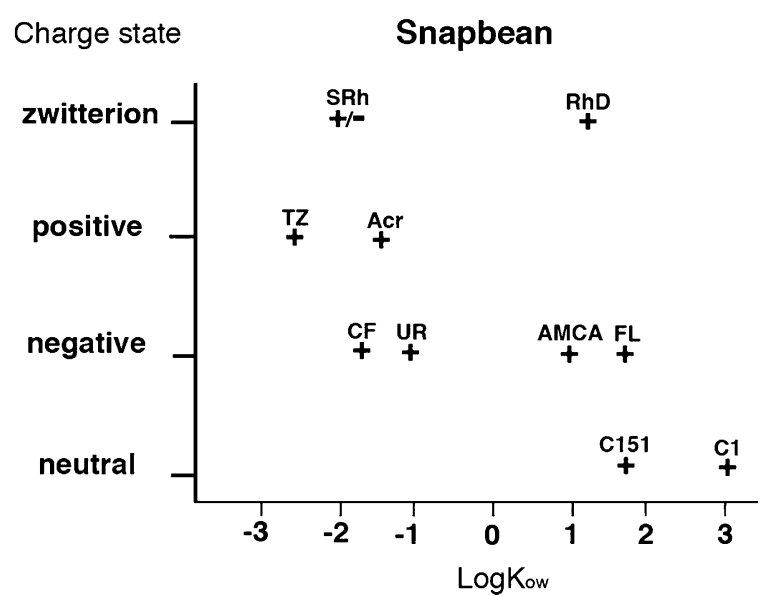

Fig. 1. Permeability of snapbean seedcoat to applied model tracer compounds of different $\log K_{\text {ow }}$ and electrical charge. The abbreviations refer to compounds listed in Table 1 . Seedcoat permeability to a particular compound was positive '+' or negative '-'. 


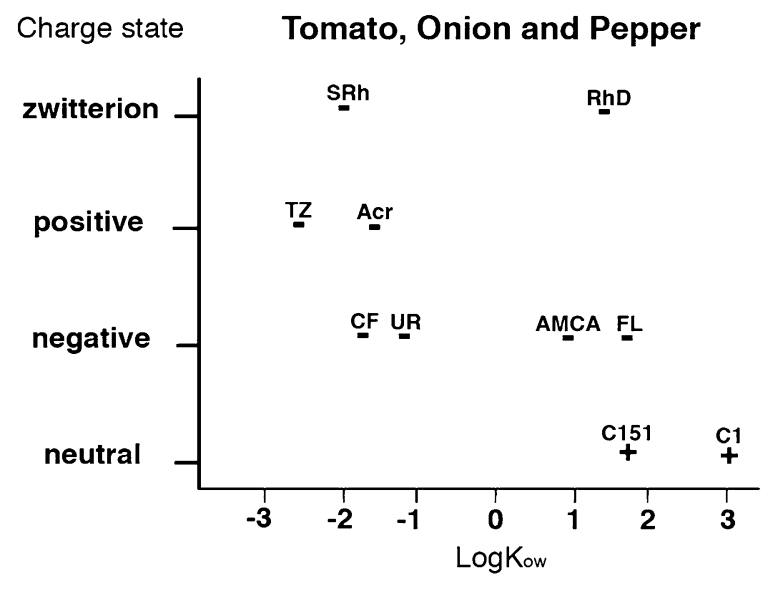

Fig. 2. Permeability of onion, tomato, and pepper seedcoats to applied model tracer compounds of different $\log K_{\mathrm{ow}}$ and electrical charge. The abbreviations refer to compounds listed in Table 1. Seedcoat permeability to a particular compound was positive '+' or negative '-'.

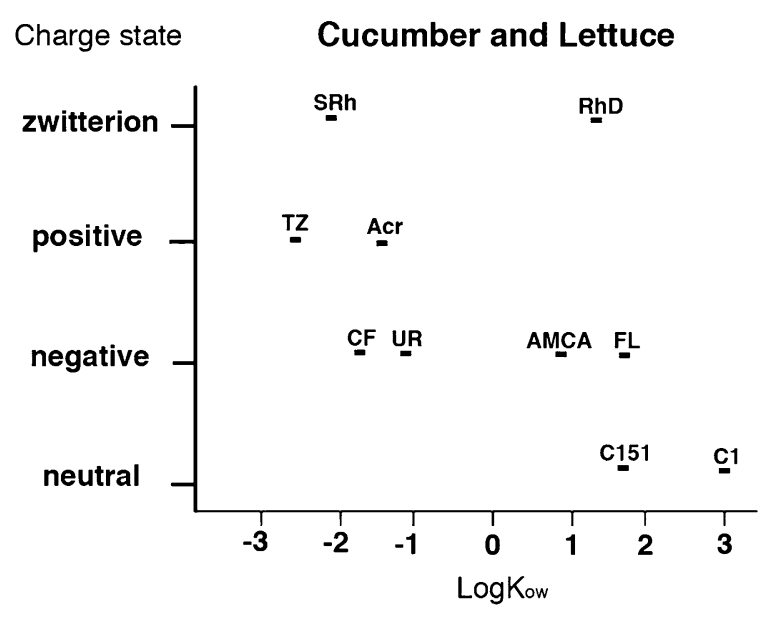

Fig. 3. Permeability of cucumber and lettuce seedcoats to applied model tracer compounds of different $\log K_{\text {ow }}$ and electrical charge. The abbreviations refer to compounds listed in Table 1. Seedcoat permeability to a particular compound was positive '+' or negative '-'.
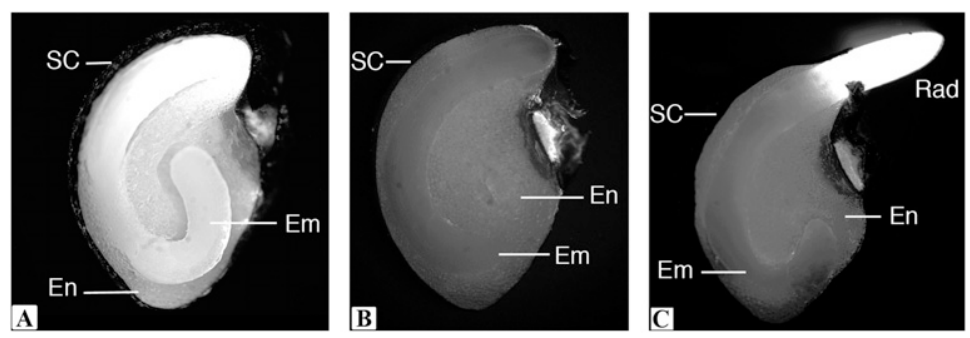

Fig. 4. Uptake of fluorescent tracers into onion seeds. (A) Dissected onion seed treated with coumarin 151 after 24-h imbibition in moist sand but before visible germination. Note bright fluorescence in endosperm and embryo tissue. $\mathrm{SC}=$ seedcoat; $\mathrm{Em}=$ embryo; $\mathrm{En}=$ endosperm. . (B) Similar to $\mathbf{A}$ but treated with rhodamine B. No fluorescence seen in the embryo or endosperm tissue. (C) Onion seed treated with rhodamine B and dissected after visible germination. Fluorescence was observed in emerged radicle (Rad).

seeds imbibed in sand moistened with water, and treated seeds revealed fluorescence in the embryo after $0.5 \mathrm{~d}$. All seeds had visibly germinated after $2 \mathrm{~d}$ when hydrated at $0 \mathrm{MPa}$. The rate of tracer uptake was slower when seeds were sown in sand moistened with $-1 \mathrm{MPa}$ or $-2 \mathrm{MPa}$ PEG solutions compared with the $0 \mathrm{MPa}$ control. However, no visible germination was recorded at either water stress by 6 d. Maintaining seeds at 100\% $\mathrm{RH}$ resulted in limited tracer penetration after
$4 \mathrm{~d}$, whereas at $6 \mathrm{~d}$, strong fluorescence was observed in the embryo. Condensation was not observed on the seeds at $100 \% \mathrm{RH}$; however, we cannot rule out that liquid water was present on the seed surface.

\section{Mobility of fluorescent tracers within cucumber seedling tissues}

Mobility of fluorescent tracers within seedling plant tissues was related to the physicochemical properties of the tracer. The nonionic,
Table 2. Diffusion of coumarin 1 through snapbean seedcoats sown in sand adjusted to $0,-1$, or -2 MPa or placed at $100 \%$ relative humidity.

\begin{tabular}{lcccc}
\hline & $0.5 \mathrm{~d}$ & $2 \mathrm{~d}$ & $4 \mathrm{~d}$ & $6 \mathrm{~d}$ \\
\hline $0 \mathrm{MPa}$ & + & $\mathrm{G}$ & $\mathrm{G}$ & $\mathrm{G}$ \\
$-1 \mathrm{MPa}$ & - & + & + & + \\
$-2 \mathrm{MPa}$ & - & + & + & + \\
$100 \%$ relative humidity & - & - & $\mathrm{F} /+$ & + \\
\hline
\end{tabular}

$\mathrm{F}=$ faint; $\mathrm{G}=$ seeds germinated.

lipophilic compound, coumarin 151, was found to be xylem-mobile and was detected in roots, shoots, petioles, cotyledons, and first true leaves (Fig. 5). Similar uptake patterns were observed in cucumber for coumarin 1 and rhodamine B (not shown). Fluorescence was not detected in the phloem so downward movement would not occur to the roots. However, detection of the tracer in the roots was attributed to the compound diffusing from the treated seed into the sand and then subsequently taken up by the root in the xylem.

\section{Discussion}

Snapbean seedcoats were permeable to most applied compounds, but with limited permeability to sulforhodamine B (Fig. 1). The restricted uptake of sulforhodamine B may be attributed to its relatively large molecular weight and large number of $\mathrm{H}$-bond acceptors (Table 1). Similar to snapbeans, soybean (Salanenka and Taylor, 2009), and pea (data not shown) had permeable seedcoats. Collectively, large-seeded legumes have permeable seedcoats to a wide range of applied compounds because they do not possess a semipermeable layer in their seedcoats (Salanenka and Taylor, 2008).

Tomato, pepper, and onion seedcoats were only permeable to the nonionic moderate lipophilic tracers, coumarin 1 and coumarin 151 (Fig. 2). These seeds have barriers in their seedcoats that restrict the diffusion of water-soluble compounds such as amino acids known as semipermeable layers (Taylor et al., 1995). The barrier layers of the seedcoat of these seeds were investigated and composed of suberin in tomato and pepper and cutin in onion (Beresniewicz et al., 1995). Switchgrass (Panicum virgatum) had the same permeability characteristics as tomato, pepper, and onion (Salanenka and Taylor, 2009). Similar to these vegetable crop seeds, many grasses have a semipermeable cutinized or suberized membrane in the caryopsis integument that restricts solute transport through the seedcoat (Simpson, 1990).

Lettuce seeds were not permeable to any applied compound (Fig. 3). Lettuce seeds have a semipermeable endosperm envelope surrounding the embryo that restricts solute diffusion (Klein et al., 1971; Speer and Hsiao, 1975). According to Speer and Hsiao (1975), the endosperm of lettuce excludes compounds with molecular weight more than $300 \mathrm{Da}$. Coumarin 1 and coumarin 151 with molecular weights $229 \mathrm{Da}$ and $203 \mathrm{Da}$, respectively, did not diffuse into the embryo. This discrepancy 

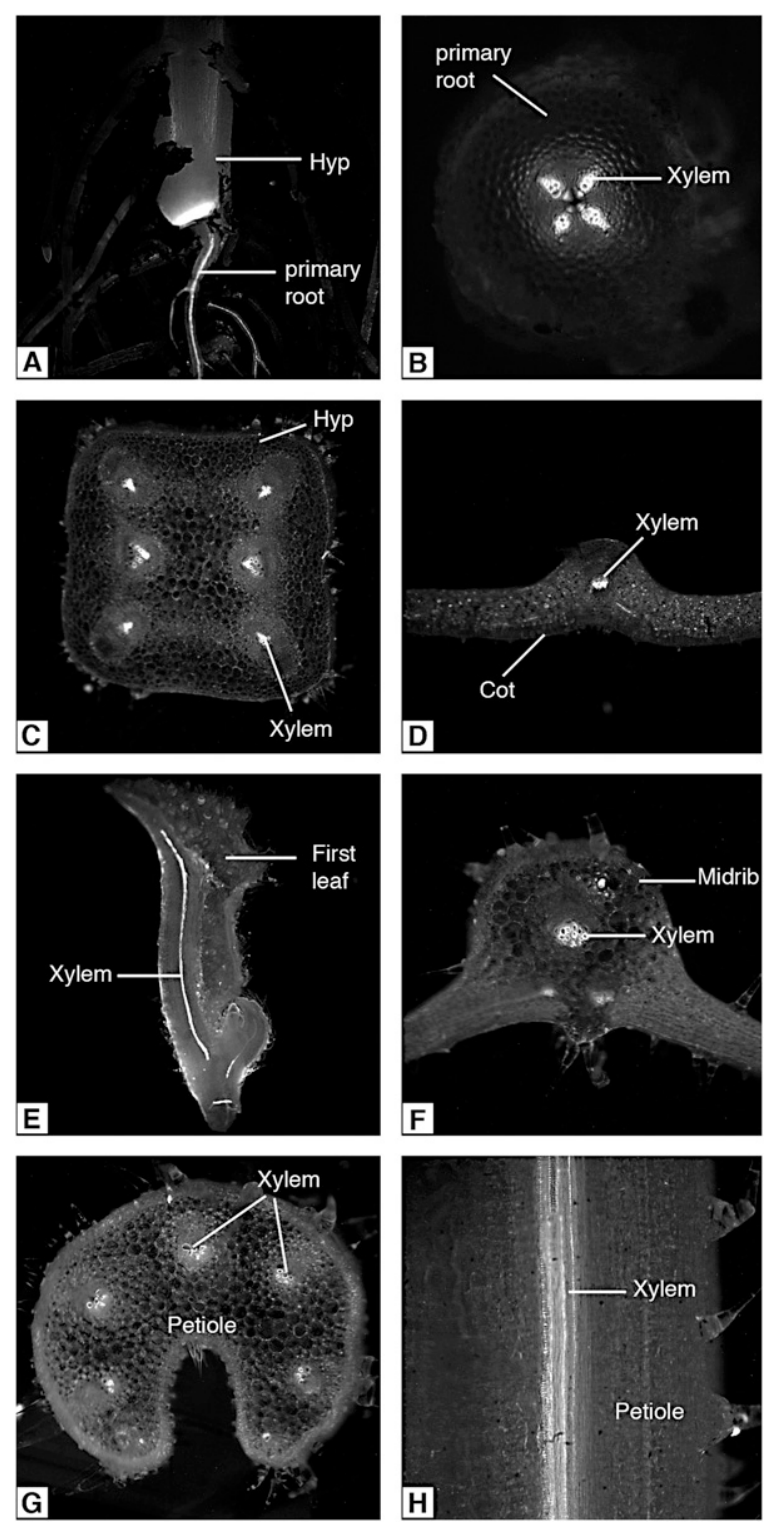

Fig. 5. Distribution of coumarin 151 applied as a seed treatment to cucumber seeds in subsequently in seedlings. (A) An underground part of cucumber plant observed with a dissecting microscope under ultraviolet light. Hyp = hypocotyl. (B-H) Hand sections of different parts of the cucumber seedling showing accumulation of the tracer in xylem vessels. (B) Cross-section of primary root. (C) Crosssection of hypocotyl (Hyp). (D) Cross-section of cotyledon (Cot). (E) Longitudinal section through first true leaf. (F) Cross-section through midrib of the first true leaf. (G) Cross-section of petiole of the first true leaf. (H) Longitudinal section through the vascular bundle of petiole.

suggests that molecular weight is not the only factor limiting uptake. Non-permeability in cucumber seedcoats was attributed to a semipermeable layer (water passes through but solutes are retained) in the perisperm-endosperm envelope (Yim and Bradford, 1998). Amritphale et al. (2010) observed that some anionic and cationic dyes were capable to permeate the perisperm-endosperm envelope of cucumber seeds and concluded that dye permeability depended on size of molecule rather than on charge or lipophilicity. According to our study, no charged or neutral dyes were able to transport through perispermendosperm in the area adjacent to the cotyledons. This discrepancy may be the result of differences in seed material preparation. Amritphale et al. (2010) studied dye transport through the perisperm-endosperm envelope of autoclaved cucumber seeds, whereas we used non-autoclaved seeds. Indeed, we found that the perisperm-endosperm envelopes isolated from autoclaved cucumber seeds were permeable to all dyes used in the current study (data not shown). Cucumber seedcoat permeability was examined in further depth and a limited amount of coumarin 151 was detected only at the micropylar region of the cucumber seed (Salanenka et al., 2009). Another species with non-permeable seedcoats was castor (Ricinus communis) based on other research in our laboratory (Salanenka and Taylor, 2009).

The nonionic moderate lipophilic tracer coumarin $151\left(\log K_{\text {ow }} 1.6\right)$ was predicted to be mobile within plant tissue based on a struc- ture-activity relation model (Horobin and Rashid, 1990; Rashid et al., 1991). In support, coumarin 151 tracer displayed systemic activity within the plant and was translocated primarily through the xylem (apoplastic movement) (Fig. 5). In contrast to coumarins, the moderately lipophilic tracer rhodamine B (log $\left.K_{\text {ow }} 1.5\right)$ was only able to permeate through seedcoats of large-seeded legumes, whereas the tracer was retained in seedcoats of other crop seeds. Considering that rhodamine B in aqueous solution exists in cationic $\left(\mathrm{HR}^{+}\right)$or zwitterionic $\left(\mathrm{R}^{ \pm}\right)$forms (Mchedlov-Petrosyan and Kholin, 2004), limited seedcoat permeability of rhodamine B may be attributed to absorption of the cationic form by seedcoat lignin mediated by hydrogen bonding. Only nonionic coumarin 151 and coumarin 1 were able to pass through seedcoats of the semipermeable seeds of tomato, pepper, and onion (Fig. 2). In contrast, the anionic coumarin derivative AMCA did not permeate into tomato, pepper, and onion seeds. Taken together, there is strong evidence that the ionization status of applied compounds plays a role in seedcoat permeability, in particular those seedcoats with semipermeable barriers.

Water potential of the environment impacts diffusion of compounds through species with permeable seedcoats (Table 2). Coumarin 1 diffused through snapbean seedcoats sown at $0 \mathrm{MPa}$ in $0.5 \mathrm{~d}$, whereas decreasing the water potential of the soil media to -1 or $-2 \mathrm{MPa}$ decreased the uptake rate. Germination was not observed at low water potential after $6 \mathrm{~d}$, revealing that diffusion is independent of germination. Coumarin 1 moved through snapbean seedcoats incubated at $100 \% \mathrm{RH}$ indicating that water vapor could facilitate diffusion and that liquid water is not necessary. In the same experimental approach, similar results were obtained for soybean at both soil water potentials and $100 \% \mathrm{RH}$ incubation (Salanenka and Taylor, 2009). Evidence revealed that wheat seeds took up water vapor from soil (Wuest et al., 1999) and that imbibition of liquid water contributed to less than $15 \%$ of the total imbibed water (Wuest, 2002). Thus, diffusion of compounds into seeds with permeable seedcoats should occur under field conditions.

There are concerns in the seed industry with seed treatment actives and formulations causing phytotoxicity (Taylor et al., 2001). To determine if a systemic a.i. of seed treatment permeates through seedcoat during seed storage that might be a reason of the phytotoxicity, snapbean and soybeans were treated with coumarin compounds and incubated at $75 \% \mathrm{RH}$ to simulate seed storage conditions at high moisture conditions. Coumarin $1 \mathrm{did}$ not diffuse through the seedcoats of either species after 1 year (data not shown), indicating that moderately lipophilic seed treatments would not diffuse to the embryo during seed storage. Based on these observations, increased phytotoxicity of a particular seed treatment appears to be a consequence of lower seed vigor that accompanies seed aging in storage and not direct contact of the compound with the embryo before imbibition. 
Results presented in this article have practical implications for seed enhancement technologies (Taylor et al., 1998) such as seed priming or soaking. A long-term objective of many people working with seeds is to incorporate a wide range of solutes into seeds by soaking or other controlled hydration methods to benefit subsequent germination and seedling growth or to disinfect seeds. However, the innate seedcoat permeability can attenuate diffusion of compounds from the soak environment to the embryo. Collectively, seed species with selectively permeable or non-permeable seed-covering tissues may only benefit from water uptake and not the particular chemical compound.

In summary, seedcoat permeability to solutes was grouped into three categories: 1 ) permeable; 2) selectively permeable; and 3) non-permeable. Snapbean seedcoats were permeable to a wide range of applied chemicals, whereas tomato, pepper, and onion had selective permeability that only allowed penetration of nonionic compounds with moderate lipophilicity. Lettuce and cucumber had non-permeable seedcoats to applied compounds. Therefore, systemic uptake by seeds with a semipermeable or non-permeable layer occurred through the roots.

\section{Literature Cited}

Amritphale, D., P. Ramakrishna, B. Singh, and S.K. Sharma. 2010. Solute permeation across the apoplastic barrier in the perisperm-endosperm envelope in cucumber seeds. Planta 231:14831494.

Bardner, R. 1964. The uptake of phorate, a systemic insecticide, applied as a slurry to wheat and mustard seeds. Ann. Appl. Biol. 53:445-458.

Beresniewicz, M.M., A.G. Taylor, M.C. Goffinet, and W.D. Koeller. 1995. Chemical nature of a semipermeable layer in seed coats of leek, onion (Liliaceae), tomato and pepper (Solanaceae). Seed Sci. Technol. 23:135-145.

Briggs, G., R. Bromilow, and A. Evans. 1982. Relationships between lipophilicity and root uptake and translocation of non-ionised chemicals by barley. Pestic. Sci. 13:495-504.

Briggs, G.G. Predicting uptake and movement of agrochemicals from physical properties. Presented at SCI Meeting: Uptake of Agrochemicals and Pharmaceuticals, Belgrave Square, London, UK, 9 Dec. 1997.

Edgington, L.V. 1981. Structural requirements of systemic fungicides. Annu. Rev. Phytopathol. 19: 107-124.
Edgington, L.V. and C.A. Peterson. 1977. Systemic fungicides: Theory, uptake, and translocation, p. 51-89. In: Siegel, M. and H.D. Sisler (eds.). Antifungal compounds. Vol. 2. Marcel Dekker, New York, NY.

Gilliland, J.W., K. Yokoyama, and W.T. Yip. 2005. Solvent effect on mobility and photostability of organic dyes embedded inside silica sol - gel thin film. Chem. Mater. 17:6702-6712.

Hansen, J.R. and K.P. Buchholtz. 1952. Absorption of 2,4-D by corn and pea seeds. Agron. J. 44:493496.

Hocombe, S.D. 1968. Uptake of atrazine by germinating seeds of turnip (Brassica rapa L). Weed Res. 8:68-71.

Horobin, R.W. and F. Rashid. 1990. Interactions of molecular probes with living cells and tissues. Part 1. Some general mechanistic proposals, making use of a simplistic Chinese box model. Histochem. Cell Biol. 94:205-209.

Horobin, R.W., J.C. Stockert, and F. Rashid-Doubell. 2006. Fluorescent cationic probes for nuclei of living cells: why are they selective? A quantitative structure-activity relations analysis. Histochem. Cell. Biol. 126:165-175.

Kasnavia, T., D. Vu, and D.A. Sabatini. 1999 Fluorescent dye and media properties affecting sorption and tracer selection. Ground water 37 : $1-6$.

Klein, S., M. Negbi, A. Witztum, and L. Rothberg. 1971. The role of the endosperm in uptake and distribution of exogenous leucine in germinating lettuce seeds. New Phytol. 70:143-147.

Lipinski, C.A., F. Lombardo, B.W. Dominy, and P.J. Feeney. 1997. Experimental and computational approaches to estimate solubility and permeability in drug discovery and development settings. Adv. Drug Deliv. Rev. 23:325 .

Liu, Z.Q. and R.E. Gaskin. 2004. Visualization of uptake of two model xenobiotics into bean leaves by confocal laser scanning microscopy: diffusion pathways and implication in phloem translocation. Pest Manag. Sci. 60:434-439.

Mchedlov-Petrosyan, N.O. and Y.V. Kholin. 2004 Aggregation of rhodamine B in water. Russ. J. Appl. Chem. 77:414-422.

Michel, B.E. 1983. Evaluation of the water potentials of solutions of polyethylene glycol 8000 both in the absence and presence of solutes. Plant Physiol. 72:66-70.

Mitchell, J.W. and J.W. Brown. 1947. Relative sensitivity of dormant and germinating seeds to 2,4-D. Science 106:266-267.

Nault, B.A., A.G. Taylor, M. Urwiler, T. Rabaey, and W.D. Hutchison. 2004. Neonicotinoid seed treatments for managing potato leafhopper infestations in snap bean. Crop Prot. 23:147-154

Rashid, F., R.W. Horobin, and M.A. Williams. 1991. Predicting the behaviour and selectivity of fluorescent probes for lysosomes and related structures by means of structure-activity models. Histochem. J. 23:450-459.

Rubin, B. and Y. Demeter. 1986. Dipropetryn absorption during germination by cucurbit seeds and its influence on seedling growth. Weed Res. 26:333-340.

Salanenka, Y.A., M.C. Goffinet, and A.G. Taylor. 2009. Structure and histochemistry of the micropylar and chalazal regions of the perisperm-endosperm envelope of cucumber seed associated with solute permeability and germination. J. Amer. Soc. Hort. Sci. 134:479-487.

Salanenka, Y.A. and A.G. Taylor. 2008. Seed coat permeability and uptake of applied substances. Acta Hort. 782:151-154.

Salanenka, Y.A. and A.G. Taylor. 2009. Uptake of model compounds by soybean, switchgrass and castor seeds applied as seed treatments, p. 76 81. In: Biddle, A.J. (ed.). Seed production and treatment in a changing environment. Symposium Proc. No. 83. The Brit. Crop Protect. Council, Alton, Hampshire, UK.

Simpson, G.M. 1990. Seed dormancy in grasses. Cambridge University Press, Cambridge, UK. p. 83-94.

Speer, H.L. and A.I. Hsiao. 1975. Some physical and chemical properties of the lettuce seed endosperm. Can. J. Bot. 54:1512-1522.

Taylor, A.G. 2003. Seed treatments, p. 1291-1298. In: Thomas, B., D.J. Murphy, and B.G. Murray (eds.). Encyclopedia of applied plant sciences. Elsevier Acad. Press, Oxford, UK.

Taylor, A.G., P.S. Allen, M.A. Bennett, K.J. Bradford, J.S. Burris, and M.K. Misra. 1998. Seed enhancements. Seed Sci. Res. 8:245-256.

Taylor, A.G., C.J. Eckenrode, and R.W. Straub. 2001. Seed treatments for onions: Challenges and progress. HortScience 36:199-205.

Taylor, A.G., S.S. Lee, M.B. Beresniewicz, and D.H. Paine. 1995. Amino acid leakage from aged vegetable seeds. Seed Sci. Technol. 23:113-122.

Tice, C.M. 2001. Selecting the right compounds for screening: Does Lipinski's rule of 5 for pharmaceuticals apply to agrochemicals? Pest Manag. Sci. 57:3-16.

Wang, N., S-M. C. Lau, G. Rogers, and T. Ray. 2000. A new method for rapid screening for xenobiotic phloem mobility in plants. Aust. J. Plant Physiol. 27:835-843.

Wuest, S.B. 2002. Water transfer from soil to seed: The role of vapor transport. Soil Sci. Soc. Amer. J. 66:1760-1763.

Wuest, S.B., S.L. Albrecht, and K.W. Skirvin. 1999. Vapor transport vs. seed-soil contact in wheat germination. Agron. J. 91:783-878.

Yim, K.O. and K.J. Bradford. 1998. Callose deposition is responsible for apoplastic semipermeability of the endosperm envelope of muskmelon seeds. Plant Physiol. 118:83-90. 